
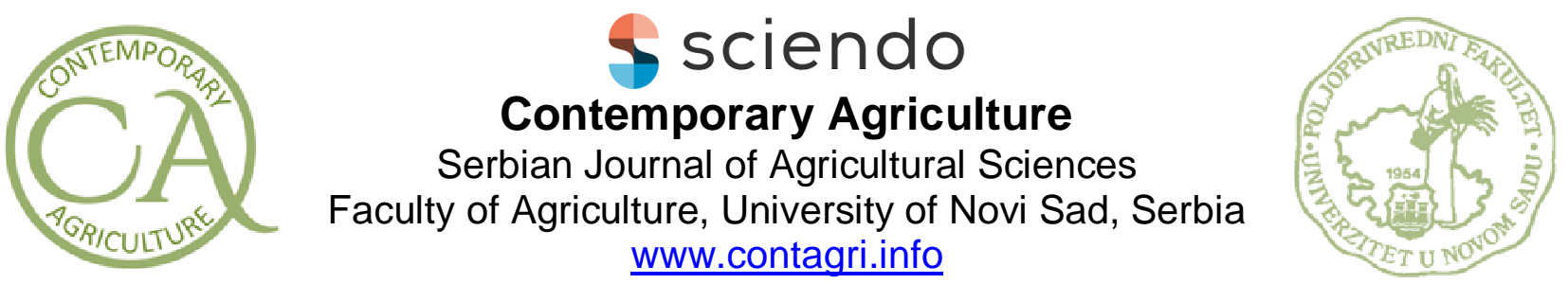

Original scientific paper

UDC: 582.736 .3

DOI: $10.2478 /$ contagri-2020-0009

\title{
EFFECTS OF NITROGEN FERTILIZATION ON MYCORRHIZAL INFECTION, NODULATION AND GROWTH OF PHASEOLUS VULGARIS L.
}

\author{
LAHOUARIA MOUNIA MANSOURI ${ }^{*}$, ABDENOUR KHELOUFI ${ }^{1}$, RABAH BELATRECHE ${ }^{1}$, \\ IMENE ABDOU ${ }^{2}$, ZINEB FAIZA BOUKHATEM ${ }^{3}$, HELEILI NOUZHA \\ ${ }^{1}$ University of Batna 2, Department of Ecology and Environment, Batna 05078, Algeria \\ ${ }^{2}$ University of Batna 1, Department of Chemistry, Batna 05000, Algeria \\ ${ }^{3}$ University of Oran 1, Department of Biotechnology, Oran 31000, Algeria \\ ${ }^{4}$ University of Batna 1, Department of Veterinary Sciences, Batna 05000, Algeria \\ Corresponding author:1.mansouri@ univ-batna2.dz
}

\begin{abstract}
SUMMARY
The common bean (Phaseolus vulgaris L.) has been the subject of a number of studies and has been described by many authors as a legume with low nitrogen fixing potential compared to other legume species. The first objective of this study is to assess the development and growth of P. vulgaris L. var. Djedida and its yield at different developmental stages (vegetative, flowering and fruiting), in the presence and absence of nitrogen fertilizer (Urea 46) in an arid climate and in a soil containing high level of $\mathrm{CaCO}_{3}$ and assimilable phosphorus. The second objective is to carry out a survey on nodulation, number of spores and mycorrhizal infection under these conditions. The results showed that the nitrogen fertilizer amendment is mainly significant ( $p<0.0001)$ for various morphological parameters. Indeed, great improvement was observed on the majority of the morphological parameters with considerable percentages. However, no significant effect was reported for the roots length. In addition, a negligible number of nodules were obtained in the plot without fertilization and no significant effect on the number of spores was recorded. Furthermore, the effect of fertilization on the arbuscular intensity $(a \%, A \%)$ and on mycorrhizal colonization $(M \%, m \%)$ of the roots was found to be significant. The soil in the arid region of Biskra showed significant mycorrhizogenic potential, although the conditions in this region were not very favorable for their development, which could constitute an effective biological resource to improve the tolerance of host plants to biotic and abiotic constraints.
\end{abstract}

Key words: common bean, urea, nodulation, endomycorrizae, abiotic and biotic stress

\section{INTRODUCTION}

Food legumes occupy an important place in the cropping systems of arid and semi-arid regions. According to Alkama (2010), cultivation of common bean (Phaseolus vulgaris L.) can play an important role in agricultural systems in Algeria, although its production remains marginalized by high instability of yields due to water deficit and phosphorus deficiency, which characterize most of the Mediterranean regions. In addition to these constraints, it is estimated that around 5 to $30 \%$ of the regions producing common bean are affected by soil salinity (Egamberdieva, 2011, Mansouri \& Kheloufi, 2017; Mansouri et al., 2019). Indeed, salinity can inhibit growth and reduce common bean yield due to ionic toxicity and imbalance, and reduced plant water potential (Kouadria et al., 2020).

In order to alleviate these environmental conditions and increase yields, farmers use chemical fertilizers. However, the farmers lack the necessary knowledge of soil properties, so these actions affect the physico-chemical and microbiological properties of the soil in the long term (Yoganathan et al., 2017). This change in soil microorganism 
diversity and density is reflected in a profound change in soil fertility (Piazza et al., 2019). Mycorrhizal fungi and nitrogen-fixing bacteria are among the microbiological indicators most sensitive to changes in availability of nutrients in the soil (Oros-Ortega et al., 2020). Indeed, these two components are strongly involved in the biogeochemical cycle and improvement of plant growth (Lu \& Hedin, 2019). In addition, numerous research studies have shown that the development and productivity as well as the quality of common bean pods are strongly related to the symbiosis that the plant establishes with beneficial soil microorganisms including nitrogen-fixing bacteria and endomycorrhizal fungi with vesicles and arbuscular (Massa et al., 2020).

In this context, this paper will allow the comparison of the yields of Phaseolus vulgaris L. in two plots with or without nitrogen fertilization. It would determine if the symbiosis could first be expressed in the arid climate, and then if it has covered the nitrogen requirements of the plant. At the same time, this will help to assess the potential of vesicle and arbuscular mycorrhizal fungi during various stages of the common bean growth. Several hypotheses can arise regarding the yield of the fertilized plot. Lower yield in the unfertilized plot will indicate that the functioning of the symbiosis is limiting. These needs may however be low, if the plant yield is strongly related to a factor other than nitrogen nutrition. On the other hand, low yield in the fertilized plot will suggest that further amendments to the crop should be made immediately. The first objective of this paper aims to assess the development and yield of common bean (Phaseolus vulgaris L. var Djedida) during its different phases of development (vegetative, flowering and fruiting), with and without nitrogen fertilizer in the arid climate of an Algerian arid region. The second objective is to carry out a survey on the nodulation, the number of spores, and mycorrhizal infection under these same conditions.

\section{MATERIAL AND METHODS}

\section{Cultural site location}

This study was carried out during the 2018 growing season on an agricultural land in Aïn Naga, a city located in the arid region of Biskra (southeast of the capital Algiers) in Algeria. Precisely, this site is located at the latitude of $34^{\circ} 43^{\prime} 16.24^{\prime \prime} \mathrm{N}$ and the longitude of $6^{\circ} 14^{\prime} 38.95^{\prime \prime} \mathrm{E}$ for an altitude of $25 \mathrm{~m}$. Biskra is located in an arid region according to the De Martonne aridity index. According to the climate data (1980-2018), the climate of Biskra is characterized by very hot and dry summers with an average temperature of $43.4{ }^{\circ} \mathrm{C}$ and an average relative humidity of $12 \%$. Winters are very cold (average minimum temperature $4{ }^{\circ} \mathrm{C}$ and average maximum relative humidity $89 \%$ ). Total annual precipitation is $160.6 \mathrm{~mm}$ with an average of 30 rainy days during the year (WCD Tutiempo, 2019).

The meteorological conditions prevailing during the experimental period are shown in Table 1. According to this table, the amount of precipitation is low. The climatic conditions recorded during our study represent an advantage as heavy rains could disturb our experimental design, especially if the nitrogen fertilizer moved towards the plot aimed to represent the control (without fertilization).

Table 1. Climatic data during the experimental period at the arid region of Aïn Naga (Biskra, Algeria)

\begin{tabular}{llccc}
\hline \multirow{2}{*}{ Climatic parameters } & \multicolumn{3}{c}{ Months (Year 2018) } \\
\cline { 2 - 5 } Precipitations & Quantity (mm) & September & October & November \\
\cline { 2 - 5 } & Number of rainy days & 1 & 27.7 & 0.76 \\
\cline { 2 - 5 } Temperature $\left({ }^{\circ} \mathrm{C}\right)$ & Maximum & 35.9 & 27.1 & 21.6 \\
& Average & 30.4 & 22.1 & 16.7 \\
& Minimum & 25.1 & 17.4 & 12.1 \\
\hline Relative humidity $(\%)$ & 42.8 & 54.4 & 56.3 \\
\hline
\end{tabular}

Source: WCD Tutiempo, 2019

The cultural site intended for this study had not been exploited for three years by any plant crops. This plot $(6 \times 8 \mathrm{~m})$ was divided into two subplots intended for the two fertilization treatments. The results of the soil analysis (at 25-30 $\mathrm{cm}$ depth) before the experiment revealed $\mathrm{pH}$ of $7.7 ; 0.17 \%$ Nitrogen $\left(\mathrm{N}_{\text {total }}\right) ; 182.8 \mathrm{mg} / \mathrm{kg}_{\text {soil }}$ Phosphorus $\left(\mathrm{P}_{2} \mathrm{O}_{5}\right)$ and $1.22 \mathrm{meq} / \mathrm{kg}_{\text {soil }}$ Potassium. The soil has a silty texture with an electrical conductivity of $2.58 \mathrm{~ms} / \mathrm{cm}$. This high electrical conductivity attributed to high soil salinity is due to high concentration of calcium ions $\left(20.3 \mathrm{meq} / 100 \mathrm{~g}_{\text {soil }}\right)$ compared to $\mathrm{Mg}^{+2}\left(1.36 \mathrm{meq} / 100 \mathrm{~g}_{\text {soil }}\right), \mathrm{K}^{+}\left(1.18 \mathrm{meq} / 100 \mathrm{~g}_{\text {soil }}\right)$ and $\mathrm{Na}^{+}\left(1.25 \mathrm{meq} / 100 \mathrm{~g}_{\text {soil }}\right)$. The soil is classified as very calcareous with $53.1 \%$ of total $\mathrm{CaCO}_{3}$. These analyzes were carried out at the Laboratory of Physical and Chemical Analysis of Water and Soils (Limited Liability Company Echems Hydro-Construction, Batna, Algeria). 


\section{Biological material}

This study focused on one variety of common bean (Phaseolus vulgaris L. var. Djedida). This variety is the most dominant on the agricultural market and the most cultivated in Algeria. Seeds (length: $12.9 \pm 0.63 \mathrm{~mm}$; width: $6.46 \pm$ $0.51 \mathrm{~mm}$; thickness: $5.69 \pm 0.42 \mathrm{~mm}$; mean $\pm \mathrm{SE} ; \mathrm{n}=50$ ) were provided by SARL AgroSeed (Harvest date: 2016; seed conditioning: France; origin: USA; reference: DJ0512). The one-thousand-seed weight was $273 \mathrm{~g}$ (Mansouri et al., 2019). Seeds were treated with Thiram (a non-systemic fungicide). The seed maturity of this variety is 85-100 days.

\section{Fertilization}

The nitrogen fertilizer was supplied in the form of granulated urea for the fertilized plots. It is nitrogen fertilizer $(46 \% \mathrm{~N})$ entirely in urea form. In the form of water-soluble granules, it provides a very rich nitrogen supply for crops with very good spreadability due to its homogeneous and regular particle size (1.8 $\mathrm{mm}$ of average diameter). In the soil, urea must first be hydrolyzed to ammonia to be fully usable for plants. Processing speed depends on soil temperature and humidity for hours or even days after spreading. Its use requires special attention because of the phenomenon of volatilization of ammonia in the atmosphere.

\section{Experimental design and treatments}

The experiments were laid out in a randomized complete design and replicated five times for each treatment (equivalent to 5 lines, each line contained 150-160 seeds). The fertilizer formed the main plots, each measuring $(4 \times$ $3 \mathrm{~m}$ ) with $0.5 \mathrm{~m}$ alley between the lines to minimize inter-plot interference. The plots were separated by two lines of the same species (Fig. 1). The fertilization factor involved two levels: fertilized $(0.5 \mathrm{~kg}$ fertilizer/plot $)$ and unfertilized $(0 \mathrm{~kg}$ fertilizer/plot). The nitrogen fertilizer was added only one time before the flowering stage (50 days after sowing) by one week. Control plot did not receive any of the nitrogen source treatments.
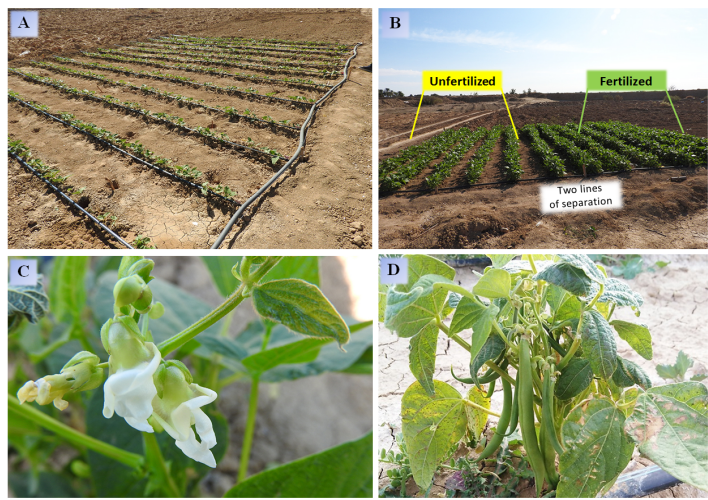

Figure 1. General overview: A - Model of drip irrigation, B - Fertilization design, C - Flowering phase, D - Fruiting phase

Land preparation was carried out manually at the end of August 2018 in two operations: plowing and harrowing. After preparing the soil, two seeds were placed in the furrows at the recommended spacing with a density of 800 seeds per line (150-160 seeds $\times 5$ lines) (Fig. 1). During the whole experiment, the plants did not receive any herbicide, pesticide or insecticide treatment. Weeds were monitored and removed manually. It should be noted that no attack of biotic origin was reported during this study.

A model for drip irrigation system was used for several reasons: fertilizer and nutrient loss is minimized due to localized application and reduced leaching; water application efficiency is high if managed correctly and field leveling is not necessary. The frequency of irrigation during the whole experiment was every 3-4 days. The two plots (fertilized and unfertilized) were separated by two lines of the same plant species (Fig. 1).

\section{Determination of growth kinetics, yield components and nodulation}

The growth kinetics concerned the three main life stages of the plants viz. vegetative, flowering and fruiting. The vegetative stage corresponded to the 2-4 leaf stage. At the completion of each growth period, plant dry biomass, shoot and root length and the number of secondary roots were assessed. The number of samples used was 20 plants $\times$ 2 plots $\times 2$ treatments $\times 3$ growth stages. Plants have been carefully dug up with a shovel on moist soil to avoid an abrupt uprooting. Shoots and roots were separated, washed several times with distilled water and oven-dried at $70{ }^{\circ} \mathrm{C}$ 
for $48 \mathrm{~h}$ for dry weight determination. It should be noted that the plant dry biomass was weighed without the flowers at the flowering stage and without the pods at the fruiting stage.

Harvesting at the end of the fruiting phase was carried out 90 days after sowing when signs of maturity were observed (yellowing of the leaves and drying of the pods). Twenty plants were randomly selected from each plot. Soil was carefully washed from the roots. The nodules were picked from the roots and their numbers and dry weight was recorded for each plant. The number of pods and seeds per plant was also evaluated (numbers and dry weight). The fresh weight of pods per plant and the number of seeds per pods were also recorded. Harvest index (\%), the ratio between dry weight of grains and the weight of total dry matter at maturity, was also calculated.

\section{Mycorrhizal infection}

For each sample of the two blocks and at each stage of $P$. vulgaris growth (vegetative, flowering and fruiting and even before sowing), $100 \mathrm{~g}$ of a composite soil mixture was analyzed by the wet sieving technique described by Gerdemann \& Nicolson (1963). The spores thus recuperated were mounted between a blade and coverslip and observed under an optical microscope (400X total magnification).

The rate of mycorrhizal colonization of $P$. vulgaris plants was estimated for the two treatments at different stages of its growth viz. the flowering and the fruiting stage. However, at the vegetative stage (2-4 leaf stage), the evaluation could not be carried out because there were only very few secondary roots.

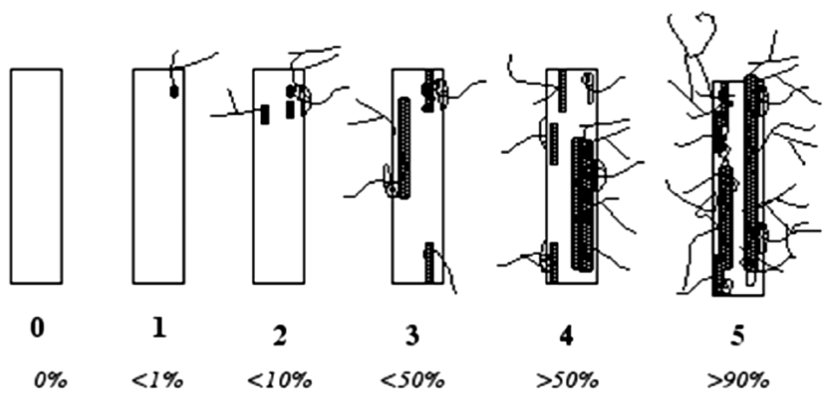

Figure 2. Notation of the degree of mycorrhization of the root fragments. Scale ranges from 0 (no mycorrhization) up to 5 (at least $90 \%$ of the fragment is mycorrhized) (Trouvelot et al., 1986)

In order to estimate the frequency of endomycorrhizal infection of the roots of $P$. vulgaris in the two blocks (with and without fertilization), the method described by Philips \& Hayman (1970) was followed. At each site, samples of thin roots were provided from the root system of P. vulgaris. These roots were well washed and placed in a $10 \%$ potassium hydroxide solution $(\mathrm{KOH})$ for 15 minutes at $90{ }^{\circ} \mathrm{C}$. They were then thoroughly washed with distilled water. The roots were then stained in a solution of $0.1 \%$ trypan blue in lactophenol for 20 minutes. All the roots thus treated were cut into several fragments of about one centimeter in length. A number of 50 fragments randomly chosen were mounted between a blade and coverslip in lactophenol at the rate of 10 fragments per slide. The fragments were then observed under an optical microscope (400X total magnification) in a drop of glycerol for endomycorrhizal frequency estimation. This made it possible to annotate them according to a class scale and thus to estimate the degree of mycorrhizal colonization of each fragment by means of six classes noted from 0 to 5 (Fig. 2) and arbuscular richness by four classes noted (A0, A1, A2 and A3) (Fig. 3).

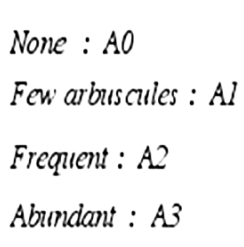

Abundant : A3

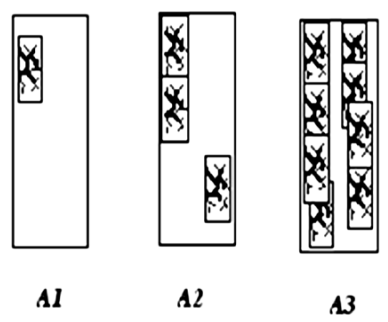

Figure 3. Notation of abundance of arbuscules in root fragments (Trouvelot et al., 1986)

A total of five parameters are calculated:

Frequency of mycorrhization (F\%): It represents the significance of the colonization of root system points. 


$$
F \%=\left(\frac{\text { number of mycorrhized fragments }}{\text { total number of fragments observed }}\right) \times 100
$$

Mycorrhization intensity (M\%): Intensity of colonization of the root cortex (proportion of the colonized cortex estimated in relation to the entire root system and expressed in \%), it reflects the importance of colonization of the root system.

$$
M \%=\frac{(95 n 5+70 n 4+30 n 3+5 n 2+n 1)}{\text { total number of fragments observed }}
$$

where $\mathrm{n} 5$ - the number of mycorrhized fragments noted in more than 95\%; $\mathrm{n} 4$ - the number of mycorrhized fragments noted from 50 to $95 \%$; 3 - the number of mycorrhized fragments noted from 30 to $50 \% ; \mathrm{n} 2$ - the number of mycorrhized fragments noted from 1 to $30 \%$; 1 - the number of mycorrhized fragments noted in $1 \%$ of the cortex. This parameter reflects better the degree of mycorrhization (Fig. 2).

Mycorrhizal intensity of mycorrhized fragments $(\mathrm{m} \%)$ : Arbuscular content of colonization in the mycorrhizal part of the root system (colonized proportion containing arbuscules).

$$
m \%=M \times\left(\frac{\text { total number of fragments observed }}{\text { number of mycorrhized fragments }}\right)=\frac{M}{F} \times 100
$$

Arbuscular intensity of the mycorrhizal part (a\%): Intensity of colonization developed in the mycorrhized part of the root system (proportion of the colonized cortex in the mycorrhized part of the root system expressed in $\%)$.

$$
a \%=M \times \frac{(100 \mathrm{~mA} 3+50 \mathrm{~mA} 2+10 \mathrm{~mA} 1)}{100}
$$

Where $\mathrm{mA} 3, \mathrm{~mA} 2, \mathrm{~mA} 1$ are $\%$ of $\mathrm{m}$ respectively affected by the notes $\mathrm{A} 3, \mathrm{~A} 2, \mathrm{~A} 1$. With:

$$
m A 3=M \times\left[\frac{(95 \mathrm{n} 5 \mathrm{~A} 3+70 \mathrm{n} 4 \mathrm{~A} 3+30 \mathrm{n} 3 \mathrm{~A} 3+\mathrm{nn} 2 \mathrm{~A} 3+\mathrm{n} 1 \mathrm{~A} 3)}{\text { number of mycorrhized fragments }}\right] \times \frac{100}{m}
$$

The same applies to $\mathrm{mA} 2$ and $\mathrm{mA} 1$.

Arbuscular intensity in the root system (A\%): Arbuscular content of colonization in relation to the entire root system (proportion of the root system containing arbuscules, expressed in \%).

$$
A \%=a \times\left(\frac{\mathrm{M}}{100}\right)
$$

\section{Statistical analysis}

The results for each variable were expressed as mean \pm standard deviation $( \pm \mathrm{SD})$. All the data were subjected to oneway and two-way analysis of variance (ANOVA) and Duncan's multiple range test ( $\mathrm{p}<0.05$ ) using SAS (Statistical Analysis System) version 9.0 (2002) software.

\section{RESULTS AND DISCUSSION}

\section{Soil characteristics before the experiment}

Granulometric analysis of the soil revealed that the soil was of fine silty structure. On the other hand, chemical analyses indicate that the soil is well supplied with organic matter (3.69\%), moderately rich in nitrogen $(0.17 \%)$ with a high C/N ratio (12.3\%). According to Fog (1988), these values indicate reduced biological activity leading to slow decomposition of organic matter. According to soil standards established by Hénin et al. (1969), the analysis of total and active $\mathrm{CaCO}_{3}$ revealed a highly calcareous soil (53.1\%). Some studies have shown that calcareous soil is useful for seed germination and growth of common bean (Ceyhan et al., 2014). Indeed, in our previous study by Mansouri et al. (2019), we found that the seeds of P. vulgaris var. Djedida were able to germinate under various concentrations and types of salt, especially under highly calcareous conditions. On the other hand, $\mathrm{CaCO}_{3}$ exerts a protective role 
against phosphoric ions against their energy absorption by free iron when $\mathrm{pH}$ approaches neutrality. According to the analysis results, the soil is basic and allows $\mathrm{CaCO}_{3}$ to combine with phosphorus and thus be available to the plant.

The $\mathrm{pH}$ of the soil studied is slightly alkaline $(7.8 \mathrm{pH})$. This $\mathrm{pH}$ is favorable for the growth of $P$. vulgaris because most common bean cultivars are sensitive to acid $\mathrm{pH}$, so the optimal $\mathrm{pH}$ is between 6.1 and 7.6. This $\mathrm{pH}$ is also favorable to microbial activity, and among these microorganisms which are able to associate with common beans are rhizobia and arbuscular endomycorrhizae. The $\mathrm{pH}$ is one of the factors limiting symbiotic fixation (Hungria \& Vargas, 2000). In rhizobia, the optimal pH for growth is between 6 and 7 (Somasegaran \& Hoben, 2012). Soil pH is also one of the main factors that affect the density and germination of spores, the formation of hyphae, and the colonization rate of arbuscular mycorrhizae (Ramírez-Viga et al., 2019; Zhang et al., 2020). Moreover, arbuscular endomycorrhizae develop at different $\mathrm{pH}$ ranges and the optimum for the majority of species is between 6 and 7 (Postma et al., 2007; Bothe et al., 2010).

The soil intended for our test is very saline with an electrical conductivity equal to $2.71 \mathrm{~ms} \mathrm{~cm}^{-1}$ which can disturb any biological activity. According to the results of the CEC (cation-exchange capacity), the soil was moderately fertile with a value of $24.3 \mathrm{meq} / 100 \mathrm{~g}_{\text {soil }}$, while $\mathrm{P}_{2} \mathrm{O}_{5}$ was $182.84 \mathrm{mg} \mathrm{kg}^{-1}$, which indicated a high value according to CRAAQ (2003). This assimilable phosphate content was an advantage for plants to tolerate abiotic stress and in the establishment of the rhizobium-legume symbiosis (Bawa, 2020). For this purpose, Tembo et al. (2019) showed that the amount of nitrogen fixed per common bean is significantly limited by the deficiency in soil phosphorus. $\mathrm{K}$ content was equal to $1.22 \mathrm{meq} \mathrm{kg}{ }^{-1}$ which was a high value. This element promotes nodulation only in the presence of sufficient quantities of phosphorus (Khanam et al., 2016).

\section{Effect of $\mathbf{N}$ fertilization on growth kinetics, yield components and nodulation}

Before the treatment, the total dry weight of the plant at the two-leaf stage recorded $0.26 \mathrm{~g}$. At this point, there is no significant difference between the two plots (Tab. 2). The absence of the amendment is to avoid predisposing young $P$. vulgaris plants to diseases such as fireblight and aphid attacks. At the flowering stage and after a week of applying nitrogen fertilization, the treatment effect was significant on the plant dry biomass $(p<0.0001)$, shoot dry biomass $(p=0.0027)$, root dry biomass $(p<0.0001)$, shoot length $(p<0.0001)$, root length $(p=0.0183)$ and the number of secondary roots $(\mathrm{p}=0.0002)$. Indeed, $\mathrm{N}$ fertilization improved the total plant dry biomass by $60 \%$, the shoot dry biomass by $65 \%$, the root dry biomass by $34 \%$, the shoot length by $37 \%$ and the root length by $16 \%$, compared to the unfertilized plants (Tab. 2). However, there was total absence of nodosities on the roots of $P$. vulgaris plants at the two-leaf stage and at the flowering stage during sampling in both treatments. The positive effect of nitrogen fertilization leads to an increase in aerial biomass but it is accompanied by a decrease in nodular biomass (De Sousa et al., 2020).

Table 2. Effect of $\mathrm{N}$ fertilization and developmental stage on some growth parameters in Phaseolus vulgaris from the arid region of Aïn Naga (Biskra, Algeria) $(\mathrm{n}=20)$

\begin{tabular}{|c|c|c|c|c|c|c|}
\hline \multirow{3}{*}{ Parameters } & \multicolumn{6}{|c|}{ Developmental Stage } \\
\hline & \multicolumn{2}{|c|}{ Vegetative } & \multicolumn{2}{|c|}{ Flowering } & \multicolumn{2}{|c|}{ Fruiting } \\
\hline & Fertilized & Unfertilized & Fertilized & Unfertilized & Fertilized & Unfertilized \\
\hline Plant Dry Biomass (g) & $0.26 \pm 0.06^{\mathrm{a}}$ & $0.26 \pm 0.06^{\mathrm{a}}$ & $6.66 \pm 1.91^{\mathrm{a}}$ & $2.62 \pm 0.78^{b}$ & $6.61 \pm 2.39^{\mathrm{a}}$ & $4.18 \pm 0.99^{b}$ \\
\hline Shoot Dry Biomass (g) & $0.19 \pm 0.05^{\mathrm{a}}$ & $0.19 \pm 0.05^{\mathrm{a}}$ & $6.47 \pm 1.42^{\mathrm{a}}$ & $2.28 \pm 0.73^{\mathrm{b}}$ & $6.22 \pm 2.28^{\mathrm{a}}$ & $3.89 \pm 0.96^{\mathrm{b}}$ \\
\hline Root Dry Biomass (g) & $0.07 \pm 0.01^{\mathrm{a}}$ & $0.07 \pm 0.01^{\mathrm{a}}$ & $0.50 \pm 0.11^{\mathrm{a}}$ & $0.33 \pm 0.07^{\mathrm{b}}$ & $0.38 \pm 0.09^{\mathrm{a}}$ & $0.28 \pm 0.07^{\mathrm{b}}$ \\
\hline Shoot Length $(\mathrm{cm})$ & -- & -- & $41.5 \pm 3.33^{\mathrm{a}}$ & $26.3 \pm 2.51^{\mathrm{b}}$ & $35.7 \pm 5.57^{\mathrm{a}}$ & $29.9 \pm 5.51^{\mathrm{b}}$ \\
\hline Root Length (cm) & -- & -- & $12.7 \pm 1.78^{\mathrm{a}}$ & $10.7 \pm 1.31^{\mathrm{b}}$ & $12.8 \pm 4.56^{\mathrm{a}}$ & $12.9 \pm 2.83^{\mathrm{a}}$ \\
\hline Number of Secondary Roots & -- & -- & $7.00 \pm 0.64^{\mathrm{b}}$ & $8.30 \pm 1.26^{\mathrm{a}}$ & $7.15 \pm 0.67^{\mathrm{b}}$ & $8.45 \pm 1.14^{\mathrm{a}}$ \\
\hline Number of pods & -- & -- & -- & -- & $13.2 \pm 3.43^{\mathrm{a}}$ & $9.35 \pm 2.18^{b}$ \\
\hline Pods Dry Weight (g) & -- & -- & -- & -- & $5.58 \pm 1.86^{\mathrm{a}}$ & $3.77 \pm 1.11^{\mathrm{b}}$ \\
\hline Number of seeds per pod & -- & -- & -- & -- & $5.47 \pm 0.65^{\mathrm{a}}$ & $4.15 \pm 0.87^{\mathrm{b}}$ \\
\hline Seeds Dry Weight (g) & -- & -- & -- & -- & $3.61 \pm 0.96^{\mathrm{a}}$ & $2.21 \pm 0.99^{\mathrm{b}}$ \\
\hline Harvest index (\%) & -- & -- & -- & -- & $52.9 \pm 12.6^{\mathrm{a}}$ & $51.1 \pm 12.2^{\mathrm{a}}$ \\
\hline
\end{tabular}

For each growth stage, the same alphabet letters along the column indicate no significant difference (Duncan Multiple Range Test)

In the fruiting phase, the treatment effect was significant on the plant dry biomass $(p=0.0002)$, shoot dry biomass $(p=0.0001)$, root dry biomass $(p=0.0414)$, shoot length $(p=0.0019)$, the number of secondary roots $(p<0.0001)$, the number of pods of per plant $(\mathrm{p}=0.0002)$, pods dry biomass $(\mathrm{p}=0.0006)$, seeds dry weight $(\mathrm{p}=0.0072)$ and the number of seed per pod $(\mathrm{p}<0.0001)$. Indeed, at this developmental stage, $\mathrm{N}$ fertilization improved the plant dry biomass by $37 \%$, shoot dry biomass by $38 \%$, root dry biomass by $26 \%$, shoot length by $16 \%$, the number of pods of 
per plant by $29 \%$, pods dry biomass by $33 \%$, seeds dry weight by $39 \%$ and the number of seeds per pod by $15 \%$ (Tab. 2). On the other hand, $N$ fertilization had no significant effect on the harvest index $(p=0.7776)$ and also on root length ( $\mathrm{p}=0.9845)$. According to Table 2 , a significant effect $(\mathrm{p}<0.0001)$ of $\mathrm{N}$ fertilization was observed on the number of secondary roots at the flowering and fruiting stage. However, fertilization reduced this number by $16 \%$ at the flowering and fruiting stage compared to the control (Tab. 2). An increase in secondary roots in the plot without nitrogen fertilization can be explained by a hypothesis of amplification of the roots in exploration for mineral nitrogen. Figure 4 shows the effect of $\mathrm{N}$ fertilization on plant growth and density at the arid region of Aîn Naga (Biskra, Algeria).

Until the fruiting stage or even maturation, there were only a small number of nodules formed on the roots of $P$. vulgaris plants not having received the nitrogen fertilizer. According to Samago et al. (2018), nodulation measurements can assess the state of the symbiosis. A small number or total absence of nodules may be due either to a low population of rhizobia in the soil, or to inhibition of nodulation by unfavorable environmental factors such as salinity. It is in line with the results of the soil analysis, as the soil is very saline with $2.71 \mathrm{~ms} \mathrm{~cm}^{-1} \mathrm{EC}$. This salinity inhibits establishment of the rhizobium-legume symbiosis during various stages of the process and in general the first stages of nodulation (Zahran, 1999). Indeed, the growth of soil rhizobia can be affected by saline stress by restricting root colonization, infection inhibition, nodule production and functioning (Sharma et al., 2020).

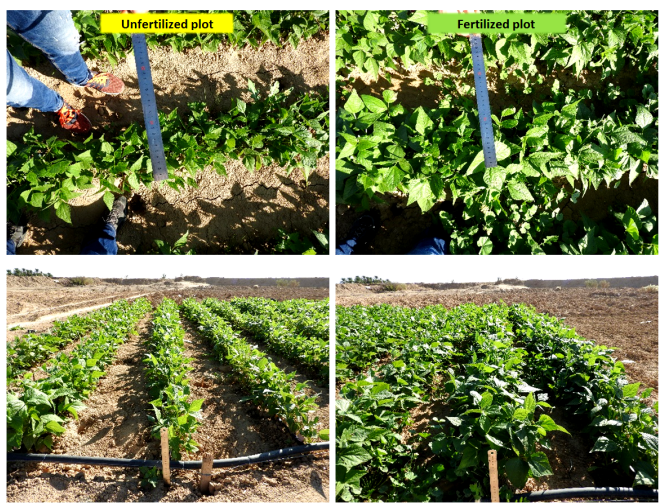

Figure 4. Plants of $P$. vulgaris var. Djedida showing the effect of $\mathrm{N}$ fertilization on plant growth and density in the arid region of Aïn Naga (Biskra, Algeria)

Two other hypotheses can explain the insignificant number of nodules on the common bean roots. The first is that of high temperatures as the region of Biskra is known for its high temperatures. In September 2018, during the common bean cultivation, the maximum recorded temperature was $35.9{ }^{\circ} \mathrm{C}(\mathrm{Tab} .1)$. The nodulation capacity and the activity of the nitrogenase from $P$. vulgaris were inhibited at a temperature of $35^{\circ} \mathrm{C}$ and above (Hungria \& Franco, 1993). The second hypothesis is related to possible incompatibility of the native strains of rhizobia with the genotype of the variety used which is a non-local variety. On the other hand, the modern cultivars are selected on European soils and for their ability to establish a symbiosis with efficient strains.

Other observations at the three samplings carried out during the three stages of development of $P$. vulgaris are total absence of nematodes (on root part) and aphids (on the aerial part). The reason for mentioning these two phytopathogens is to expose the hypothesis of nematodes attack on common bean roots as this will affect the nitrogen-fixing symbiosis by inhibiting nodulation and limiting the fixation of atmospheric nitrogen. This nonexistence is perhaps due to the presence of endomycorrhizae which, according to several authors, could protect the plant against attack by pathogens or the effect of high temperatures or even the resistance of the cultivated variety.

We can conclude through this nodular survey that the growth of $P$. vulgaris var. Djedida requires more inorganic phosphorus than mineral nitrogen nutrition. This requirement appears particularly high in common bean, which in fact is more affected by phosphorus deficiency than other legumes species (Vadez et al., 1996).

\section{Effect of $\mathbf{N}$ fertilization on mycorrhizal infection}

\section{Spores number}

Observation of the spores by wet sieving of the soil from the two blocks (with and without nitrogen) revealed the existence of morphotypes of important Glomeromycota spores. The spores observed are compared to specimens of 
the collection INVAM (2019). Characteristic structures such as color, shape, presence of spore-producing bags and germination shields allow spores to be identified (Bâ et al., 1996). On the other hand, it is impossible for us to identify the spores on the basis of their morphology when their characteristic structures are absent (Bago et al., 1998). Indeed, in this study, some structural characteristic may have been lost during the spore extraction process and therefore it is difficult to assign a genus to a morphotype. This is how in our case differentiation of spores is based only on color. So we were able to distinguish spores of yellow, black, translucent white and brown color (Fig. 5).

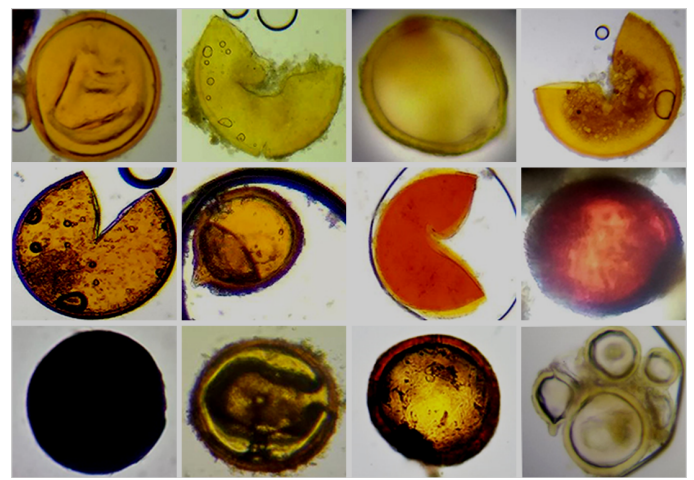

Figure 5. Microphotographs of Arbuscular Mycorrhizal Fungi spores isolated from rhizosphere soils of $P$. vulgaris var. Djedida

According to the two-way ANOVA, no significant effect ( $\mathrm{p}>0.05$ ) of $\mathrm{N}$ fertilization was indicated at the vegetative, flowering and fruiting stages and also before sowing (Fig. 6). However, a significant increase in the spore numbers was reported in the fruiting period (Fig. 6). Before sowing, the number of spores in the first plot (without fertilization) was 103 spores $/ 100 \mathrm{~g}_{\text {soil }}$, while in the second plot (with fertilization) it was $110 \mathrm{spores} / 100 \mathrm{~g}_{\text {soil }}$. At this stage, the presence of spores is a form of survival during unfavorable conditions such as insufficient nutrients or drought.

In the second sample at the two-leaf stage, the number of spores increased by 18 spores in the unfertilized plot, while in the fertilized plot the number decreases by 17 spores (Fig. 6). In the flowering period and after adding the chemical fertilizer, the number of spores remained stable in the unfertilized plot compared to the first sampling. On the other hand, in the plot which received the treatment the number of spores increased by 40 spores compared to the first sampling. At the fruiting stage, the number of spores in the unfertilized plot was slightly higher than in the second plot, reaching an average of 175 spores $/ 100 \mathrm{~g}_{\text {soil }}$ (Fig. 6). Moreover, there was an increase in the number of spores between the flowering stage and the fruiting stage from 116 to 175 spores $/ 100 \mathrm{~g}_{\text {soil }}$ in the unfertilized plot and from 140 to 159 spores $/ 100 \mathrm{~g}_{\text {soil }}$ in the fertilized plot but the effect of fertilization was not significant $(\mathrm{p}=0.7638)$.

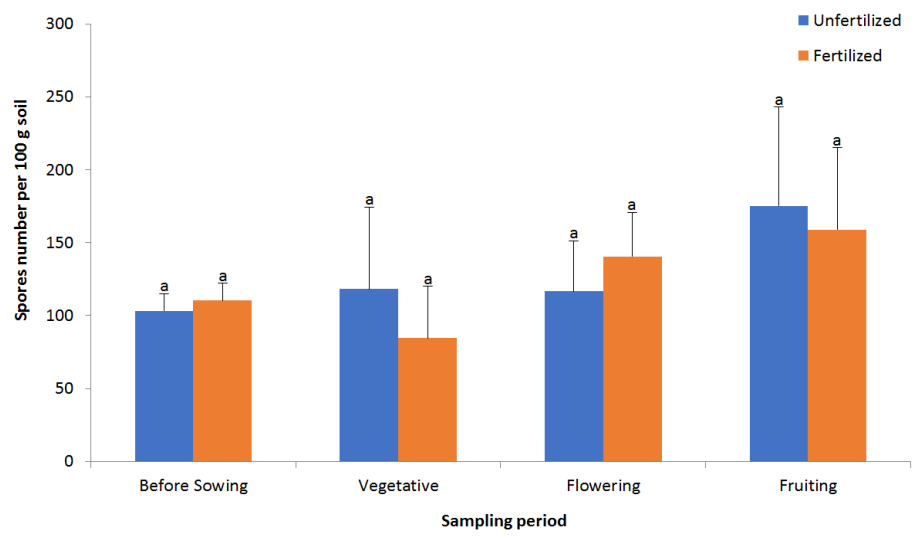

Figure 6. Effect of nitrogen fertilization (Urea 46) on the number of spores per $100 \mathrm{~g}$ of soil extracted from the common bean (P. vulgaris L. var. Djedida) rhizosphere at different growth periods (including before sowing). For each period, the same alphabet letters indicate no significant difference (Duncan Multiple Range Test) 
The number of spores in the soil depends on several factors that interfere with the physicochemical, biochemical and microbiological properties of the soil (Mahmoudi et al., 2020). It is therefore difficult to demonstrate the effect of the chemical nitrogen fertilizer on the dynamics of endomycorrhizal spores in the soil. Furthermore, Fisher et al. (2007) showed that over-fertilization with nitrogenous elements negatively influences formation of endomycorrhizal fungi spores. Gosling et al. (2006) have shown that nitrogen fertilizer (easily soluble) would reduce the colonization and/or diversity of endomycorrhizal fungi.

\section{Mycorrizal and arbuscular intensity}

The study on the frequency of mycorrhization (F\%) at the flowering and the fruiting stage remained high and stable with a rate of $100 \%$ in the two plots (with and without nitrogen fertilization) (Tab. 2). When coloring the roots of $P$. vulgaris, the presence of vesicles with spherical shape could be seen (Fig. 7C, 7D). In the presence of nitrogen fertilizer, the intensity of mycorrhizal colonization of the root cortex (M\%) reached $53.2 \%$ at the flowering stage then it increased by only $2 \%$ giving a percentage of $55.8 \%$ at the fruiting stage (Tab. 2). However, in the absence of nitrogen fertilizer, $\mathrm{M} \%$ reached $37.9 \%$ at the flowering stage, and then it increased up to $53.8 \%$ at the fruiting stage which is the same rate as the roots having received nitrogen fertilization. The effect of fertilization and the sampling period was clearly significant (Tab. 2).

The intensity of colonization developed in the mycorrhizal part of the root system (m\%) in the plot with $\mathrm{N}$ fertilization reached 53.2\% at the flowering stage and then 55.8\% at the fruiting stage. However, in the plot without fertilization and at the flowering stage, it reached $37.9 \%$ then it also increased up to $53.7 \%$ at the fruiting stage (Tab. 2). It can be deduced that the rate of $\mathrm{M} \%$ and $\mathrm{m} \%$ were proportional. Several research studies reported that endomycorrhizae contributed to the absorption of mineral elements, including mineral nitrogen (Giovannini et al., 2020). Contribution of nitrogen fertilizer promotes the intensity of colonization of the root cortex at the flowering stage so the plants require a lot of energy, including nitrogen, which can explain the increase in this intensity.

Table 2. Frequency of mycorrhization (F\%), Mycorrhization intensity (M\%), Mycorrhizal intensity of mycorrhized fragments $(\mathrm{m} \%)$, Arbuscular intensity of the mycorrhizal part (a\%) and Arbuscular intensity in the root system (A\%) in P. vulgaris var. Djedida treated with two levels of $\mathrm{N}$ fertilization $(\mathrm{n}=50)$

\begin{tabular}{llccccc}
\hline \multirow{2}{*}{ Period } & \multirow{2}{*}{ N Fertilization } & \multicolumn{3}{c}{ Mycorrhizal intensity } & \multicolumn{2}{c}{ Arbuscular instensity } \\
\cline { 3 - 6 } & & $\mathbf{F ~ ( \% )}$ & $\mathbf{M}(\%)$ & $\mathbf{m}(\%)$ & $\mathbf{a}(\%)$ & $\mathbf{A}(\%)$ \\
\hline \multirow{2}{*}{ Flowering } & Fertilized & $100^{\mathrm{a}}$ & $53.2 \pm 4.29^{\mathrm{a}}$ & $53.2 \pm 4.29^{\mathrm{a}}$ & $22.1 \pm 4.27^{\mathrm{a}}$ & $11.8 \pm 2.83^{\mathrm{a}}$ \\
& Unfertilized & $100^{\mathrm{a}}$ & $37.9 \pm 0.90^{\mathrm{b}}$ & $37.9 \pm 0.90^{\mathrm{b}}$ & $10.9 \pm 1.06^{\mathrm{b}}$ & $4.11 \pm 0.36^{\mathrm{b}}$ \\
\multirow{2}{*}{ Fruiting } & Fertilized & $100^{\mathrm{a}}$ & $55.8 \pm 9.53^{\mathrm{a}}$ & $55.8 \pm 9.53^{\mathrm{a}}$ & $18.3 \pm 9.07^{\mathrm{ba}}$ & $10.7 \pm 6.45^{\mathrm{a}}$ \\
Probability (Period) & $100^{\mathrm{a}}$ & $53.8 \pm 5.84^{\mathrm{a}}$ & $53.7 \pm 5.84^{\mathrm{a}}$ & $18.2 \pm 6.33^{\mathrm{ba}}$ & $9.73 \pm 3.33^{\mathrm{ba}}$ \\
Probability (Fertilization) & -- & 0.0098 & 0.0098 & 0.5615 & 0.2741 \\
Probability (Period $\times$ Fertilization) & -- & 0.0132 & 0.0132 & 0.0846 & 0.0468 \\
\hline \multicolumn{2}{l}{ The same alphabet letters along the column indicate no significant difference (Duncan Multiple Range Test) } \\
\hline
\end{tabular}

In the fertilized plot, the intensity of colonization in the mycorrhizal part of the root system (a\%) reached $22.1 \%$ at the flowering stage, and then it decreased at the fruiting stage up to $18.3 \%$. On the other hand, in the unfertilized plot, $(\mathrm{a} \%)$ reached $10.9 \%$ at the flowering stage and then increased up to $18.2 \%$ at the fruiting stage (Tab. 2). The arbuscular intensity of colonization in the entire root system (A\%) of the fertilized plot reached $11.8 \%$ at the flowering stage, to decrease slightly to $10.7 \%$ at the fruiting stage. However, an increase in this same parameter was observed in the control plants with a value of $4.11 \%$ at the flowering stage and $9.73 \%$ at the fruiting stage. According to the results of ANOVA, the effect of fertilization on this parameter is not significant (Tab. 2).

At the fruiting stage, it was reported that there was no significant effect of nitrogen fertilization on $P$. vulgaris plants. However, all parameters related to mycorrhizal infection viz. F\%, M\%, $\mathrm{m} \%$, a $\%$ and $\mathrm{A} \%$, were improved by the supply of nitrogen fertilizer by $29 \%, 29 \%, 51 \%$ and $65 \%$, respectively compared to the control plants. In the case of arbuscules, there is difference between the roots that have or have not received the fertilizer. The available nitrogen offers rapid mycorrhization but it decreases at the fruiting stage as the lifespan of the arbuscules is ephemeral; on the other hand, in the roots without fertilizer it starts with a low percentage but then it reaches the same percentage as in the roots having received the fertilizer (He et al., 2003). 


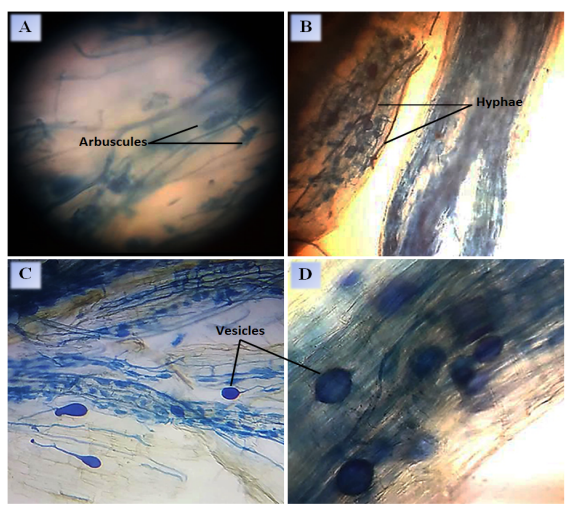

Figure 7. Microphotographs of arbuscular mycorrhizal fungi structures in root cortex P. vulgaris L. var. Djedida: A - Arbuscules, B - Hyphae (B), C-D - Vesicles

The role of arbuscules within the roots in the acquisition of nitrogen has been confirmed and several studies have shown the involvement of mycorrhizal fungi in mobilization of nutrients such as nitrogen and phosphorus from natural substrates (Plassard \& Dell, 2010). Moreover, Miransari (2011) confirmed that the arid climate favored aquization of nitrogen in a symbiotic way, where the hyphae of endomycorrhizae will take nitrogen in the form of ammonium (following the hydrolysis of urea to ammonium). It is then transformed into arginine and transported through the hyphae to the arbuscules where it is transmitted to the plant in the form of ammonium. It will be then taken up by the plant via ammonium transporters, specifically expressed during mycorrhization in arbuscules (Parniske, 2008). According to Bååth \& Spokes (1989), the nitrogen source has no influence on the reaction to mycorrhizae. At low P levels in the soil, addition of $\mathrm{N}$ does not affect the rate of mycorrhizal colonization. Likewise, a high $\mathrm{P}$ content and a low $\mathrm{N}$ content have little influence. Furthermore, germination of spores and mycorrhizal infection of $P$. vulgaris could not be inhibited despite temperatures exceeding $35{ }^{\circ} \mathrm{C}$ in Biskra, whereas temperature is one of the factors which influence the germination of spores and the root colonization (Liu et al., 2004). Indeed, Sheikh \& Sanders (1988) state that the temperature between $20{ }^{\circ} \mathrm{C}$ and $30{ }^{\circ} \mathrm{C}$ is an optimal temperature for germination of spores. On the other hand, it was observed that despite the high salinity of the soil, the common bean plants were mycorrhized, while Tian et al. (2004) and Sheng et al. (2008) reported that salinity suppresses or reduces formation of mycorrhizae. Hirrel \& Gerdemann (1980) and Sheng et al. (2008) showed that salinity negatively affects the capacity for colonization, the germination of spores and the growth of hyphae of mycorrhizal fungi. In this study, there was a relationship between the high assimilable phosphorus contents and the presence of mycorrhizal infection, whereas De Miranda \& Harris (1994) indicated that the germination of the spores of the mycorrhizal fungi is inhibited by high assimilable phosphorus content. According to Galván et al. (2009), there is often no relationship between the soil content of $\mathrm{P}$ and the number of spores.

\section{CONCLUSION}

The soil in our experiment was a saline soil, with high contents of $\mathrm{CaCO}_{3}$, low levels of organic matter and high assimilable phosphorus contents. The investigation of Phaseolus vulgaris L. var. Djedida in the presence and absence of nitrogen fertilizer on this site revealed a minimal number of nodules or almost none, which leads to several hypotheses having repercussions on the biotic and abiotic factors constraining the establishment of symbiosis. The salinity will then represent the abiotic factor, while the biotic factor is the variety, which is a nonlocal variety which may be incompatible with the native strains of the arid region of Biskra. On the other hand, application of nitrogen fertilizer before flowering had a significant effect on different morphological growth variables in $P$. vulgaris at the flowering and fruiting stages except for the length of the root and the harvest index. According to these results, we can conclude that this variety gave a good yield with a low nitrogen content but in a soil rich in phosphorus. The soil in this area has shown significant mycorrhizogenic potential, although the conditions in this region are not very favorable for their development, which could constitute an effective biological resource to improve the tolerance of host plants to biotic and abiotic constraints. Furthermore, we recommend research on the optimal amounts of $\mathrm{N}$ fertilizers in order to decrease the impact of excess chemical fertilizers on the environment and health. Further research on $\mathrm{N}_{2}$ fixation in common bean is also needed. 
Acknowledgements: This work was realized within the framework of the project "Contribution to the study of the effects of biotic and abiotic conditions on the common bean (Phaseolus vulgaris L.) rhizobial and mycorrhizal symbiosis' and was supported by SARL Green Pharm South RC 07/00-0243692B18, Biskra (Algeria).

\section{REFERENCES}

Alkama N. (2010): Adaptation de la symbiose rhizobienne chez le haricot à la déficience en phosphore: détermination de la réponse de la plante en terme d'échanges gazeux et de flux minéraux échangés avec la rhizosphère. Doctoral dissertation, Montpellier, SupAgro, France, p. 180.

Bâ A.M., Dalpé Y., Guissou T. (1996): Les Glomales d'Acacia holosericea et d'Acacia mangium. Bois \& Forets des Tropiques, 250: 5-18.

Bååth E. \& Spokes J. (1989): The effect of added nitrogen and phosphorus on mycorrhizal growth response and infection in Allium schoenoprasum. Canadian Journal of Botany, 67(11): 3227-3232.

Bago B., Azcón-Aguilar C., Goulet A., Piché Y. (1998): Branched absorbing structures (BAS): a feature of the extraradical mycelium of symbiotic arbuscular mycorrhizal fungi. The New Phytologist, 139(2): 375-388.

Bawa A. (2020): Yield Response of Cowpea to Phosphorus Fertilizer Application. Journal of Experimental Agriculture International, 42(2): 125-135.

Bothe H., Turnau K., Regvar M. (2010): The potential role of arbuscular mycorrhizal fungi in protecting endangered plants and habitats. Mycorrhiza, 20(7): 445-457.

Ceyhan E., Kahraman A., Avci M.A., Dalgic H. (2014): Combining ability of bean genotypes estimated by line x tester analysis under highly-calcareous soils. The Journal of Animal \& Plant Sciences, 24(2): 579-584.

CRAAQ (2003): Guide de référence en fertilisation. $1^{\text {ere }}$ édition. Chapitre 2. p. 20-29.

De Miranda J.C.C. \& Harris P.J. (1994): Effects of soil phosphorus on spore germination and hyphal growth of arbuscular mycorrhizal fungi. New Phytologist, 128(1): 103-108.

De Sousa M.A., de Oliveira M.M., Damin V., de Brito Ferreira E.P. (2020): Productivity and Economics of Inoculated Common Bean as Affected by Nitrogen Application at Different Phenological Phases. Journal of Soil Science and Plant Nutrition. https://doi.org/10.1007/s42729-020-00256-4

Egamberdieva D. (2011): Survival of Pseudomonas extremorientalis TSAU20 and P. chlororaphis TSAU13 in the rhizosphere of common bean (Phaseolus vulgaris) under saline conditions. Plant, Soil and Environment, 57(3): 122-127.

Fisher L.S., Mays P.A., Wylie C.L. (2007): An overview of nitrogen critical loads for policy makers, stakeholders, and industries in the United States. Water, air, and soil pollution, 179(1-4): 3-18.

Fog K. (1988): The effect of added nitrogen on the rate of decomposition of organic matter. Biological Reviews, 63(3): 433-462.

Galván G.A., Parádi I., Burger K., Baar J., Kuyper T.W., Scholten O.E., Kik C. (2009): Molecular diversity of arbuscular mycorrhizal fungi in onion roots from organic and conventional farming systems in the Netherlands. Mycorrhiza, 19(5): 317-328.

Gerdemann J.W. \& Nicolson T.H. (1963): Spores of mycorrhizal Endogone species extracted from soil by wet sieving and decanting. Transactions of the British Mycological society, 46(2): 235-244.

Giovannini L., Palla M., Agnolucci M., Avio L., Sbrana C., Turrini A., Giovannetti M. (2020): Arbuscular mycorrhizal fungi and associated microbiota as plant biostimulants: research strategies for the selection of the best performing inocula. Agronomy, 10(1): 106.

Gosling P., Hodge A., Goodlass G., Bending G.D. (2006): Arbuscular mycorrhizal fungi and organic farming. Agriculture, Ecosystems \& Environment, 113(1-4): 17-35.

He X.H., Critchley C., Bledsoe C. (2003): Nitrogen transfer within and between plants through common mycorrhizal networks (CMNs). Critical reviews in plant sciences, 22(6): 531-567.

Hénin S., Gras R., Monnier G. (1969): Le profil cultural: l'état physique du sol et ses conséquences agronomiques, Masson, Paris, p. 332.

Hirrel M.C. \& Gerdemann J.W. (1980): Improved growth of onion and bell pepper in saline soils by two vesicular-arbuscular mycorrhizal fungi. Soil Science Society of America Journal, 44(3): 654-655.

Hungria M. \& Franco A.A. (1993): Effects of high temperature on nodulation and nitrogen fixation by Phaseolus vulgaris L. Plant and Soil, 149(1): 95-102.

Hungria M. \& Vargas M.A. (2000): Environmental factors affecting N2 fixation in grain legumes in the tropics, with an emphasis on Brazil. Field crops research, 65(2-3): 151-164.

INVAM (2019): International Culture Collection of (Vesicular) Arbuscular Mycorrhizal Fungi. Available at: https://invam.wvu.edu (accessed 20.12.2019).

Khanam M., Islam M. S., Ali M. H., Chowdhury I. F., Masum S. M. (2016): Performance of soybean under different levels of phosphorus and potassium. Bangladesh Agronomy Journal, 19(1): 99-108.

Kouadria M., Sehari M., Hassani A., Koulali F., Zouablia S. (2020): Effet du stress salin sur le système foliaire d'une légumineuse vivrière (Phaseolus vulgaris L.) cultivée dans un sol de bentonite. Revue Marocaine des Sciences Agronomiques et Vétérinaires, 8(1).

Lu M. \& Hedin L.O. (2019): Global plant-symbiont organization and emergence of biogeochemical cycles resolved by evolutionbased trait modelling. Nature Ecology \& Evolution, 3(2): 239-250. 
Liu A., Wang B., Hamel C. (2004): Arbuscular mycorrhiza colonization and development at suboptimal root zone temperature. Mycorrhiza, 14(2): 93-101.

Mahmoudi N., Dias T., Mahdhi M., Cruz C., Mars M., Caeiro M. F. (2020): Does Arbuscular Mycorrhiza Determine Soil Microbial Functionality in Nutrient-Limited Mediterranean Arid Ecosystems? Diversity, 12(6): 234.

Mansouri L.M. \& Kheloufi A. (2017): Effect of diluted seawater on seed germination and seedling growth of three leguminous crops (Pea, Chickpea and Common bean). Agriculture and Forestry/Poljoprivreda i šumarstvo, 63(2):131-142.

Mansouri L.M., Heleili N., Boukhatem Z.F., Kheloufi A. (2019): Seed germination and radicle establishment related to type and level of salt in common bean (Phaseolus vulgaris L. var. Djedida). Cercetări Agronomice în MoldovalAgronomic Research in Moldavia, 52(3):262-277.

Massa N., Cesaro P., Todeschini V., Capraro J., Scarafoni A., Cantamessa S., Copetta A., Anastasia F., Gamalero E., Lingua G., Berta G., Bona E. (2020): Selected autochthonous rhizobia, applied in combination with AM fungi, improve seed quality of common bean cultivated in reduced fertilization condition. Applied Soil Ecology, 148: 103507.

Miransari, M. (2011): Arbuscular mycorrhizal fungi and nitrogen uptake. Archives of Microbiology, 193(2): 77-81.

Oros-Ortega I., Lara-Pérez L.A., Casanova-Lugo F., Díaz-Echeverría V.F., Villanueva-López G., Ramírez-Barajas P.J., Cetzal-Ix W. (2020): Diversity and Importance of the Relationship Between Arbuscular Mycorrhizal Fungi and Nitrogen-Fixing Bacteria in Tropical Agroforestry Systems in Mexico. In: Plant Microbe Symbiosis, Springer, Cham., pp. 21-34.

Parniske M. (2008): Arbuscular mycorrhiza: the mother of plant root endosymbioses. Nature Reviews Microbiology, 6(10): 763775.

Philips J.M. \& Hayman D.S. (1970): Improved procedure for declaring and staining parasitic and VAM fungi for rapid assessment of infection. Transactions of the British Mycological Society, 55: 158-161.

Piazza G., Ercoli L., Nuti M., Pellegrino E. (2019): Interaction between conservation tillage and nitrogen fertilization shapes prokaryotic and fungal diversity at different soil depths: Evidence from a 23-Year field experiment in the Mediterranean area. Frontiers in Microbiology, 10: 2047.

Plassard C. \& Dell B. (2010): Phosphorus nutrition of mycorrhizal trees. Tree Physiology, 30(9): 1129-1139.

Postma J.W., Olsson P.A., Falkengren-Grerup U. (2007): Root colonisation by arbuscular mycorrhizal, fine endophytic and dark septate fungi across a pH gradient in acid beech forests. Soil Biology and Biochemistry, 39(2): 400-408.

Ramírez-Viga T., Guadarrama P., Castillo-Argüero S., Estrada-Medina H., García-Sánchez R., Hernández-Cuevas L., SánchezGallén I., Ramos-Zapata, J. (2019): Relationship between arbuscular mycorrhizal association and edaphic variables in mangroves of the coast of Yucatán, Mexico. Wetlands, 20: 539-549.

Samago T.Y., Anniye E.W., Dakora F.D. (2018): Grain yield of common bean (Phaseolus vulgaris L.) varieties is markedly increased by rhizobial inoculation and phosphorus application in Ethiopia. Symbiosis, 75(3): 245-255.

Sharma V., Bhattacharyya S., Kumar R., Kumar A., Ibañez F., Wang J., Guo B., Sudini H.K., Gopalakrishnan S., DasGupta M., Varshney R.K., Pandey M.K. (2020): Molecular Basis of Root Nodule Symbiosis between Bradyrhizobium and 'CrackEntry'Legume Groundnut (Arachis hypogaea L.). Plants, 9(2): 276.

Sheikh N.A. \& Sanders F.E. (1988): Effect of temperature on germination mycorrhizal spores and VAM infection in roots. Biologia 34: 337-350

Sheng M., Tang M., Chen H., Yang B., Zhang F., Huang Y. (2008): Influence of arbuscular mycorrhizae on photosynthesis and water status of maize plants under salt stress. Mycorrhiza, 18(6-7): 287-296.

Somasegaran P. \& Hoben H.J. (2012): Handbook for rhizobia: methods in legume-Rhizobium technology. Springer Science \& Business Media.

Tian C.Y., Feng G., Li X.L., Zhang F.S. (2004): Different effects of arbuscular mycorrhizal fungal isolates from saline or nonsaline soil on salinity tolerance of plants. Applied Soil Ecology, 26(2): 143-148.

Tembo L., Namebo M., Chanda R., Kafwa K., Munyinda K. (2019): Genotypic Variation for Response to Phosphorus Fertilization in Common Bean Mutants. Crops, 4(1): 11-16.

Trouvelot A., Kough J.L., Gianinazzi-Pearson V. (1986): Mesure du taux de mycorhization VA d'un système radiculaire. Recherche de méthode d'estimation ayant une signification fonctionnelle. Physiological and genetical aspects of mycorrhizae: proceedings of the $1^{\text {st }}$ European symposium on mycorrhizae, Dijon, 1-5 July 1985, pp. 217-221.

Vadez V., Rodier F., Payre H., Drevon J.J. (1996): Nodule permeability to $\mathrm{O}_{2}$ and nitrogenase-linked respiration in bean genotypes varying in the tolerance of $\mathrm{N}_{2}$ fixation to $\mathrm{P}$ deficiency. Plant physiology and biochemistry (Paris), 34(6): 871878.

WCD Tutiempo (2019): World Climate Data Tutiempo. Available at: https://fr.tutiempo.net/climat/2019/ws-605250.html (accessed 25.11.2018).

Yoganathan K., Ganesh P., Tamizhazhagan V. (2017): Impact of organic and conventional (chemical) fertilization on soil quality and its seasonal variation. International Journal of Zoology and Applied Biosciences, 2(6): 348-355.

Zahran H.H. (1999): Rhizobium-legume symbiosis and nitrogen fixation under severe conditions and in an arid climate. Microbiology and Molecular Biology Reviews, 63(4): 968-989.

Zhang H.S., Zhou M.X., Zai X.M., Zhao F.G., Qin P. (2020): Spatio-temporal dynamics of arbuscular mycorrhizal fungi and soil organic carbon in coastal saline soil of China. Scientific Reports, 10(1): 1-13.

Submitted: 27.3 .2020 .

Accepted: 18.6.2020. 